\title{
To evaluate the Effect and Comparison of Superoxidised Solution (Oxum) V/S Povidone Iodine (Betadine) in Healing of Wounds
}

\author{
Dr. H. V.Nerlekar ${ }^{1}$, Dr. Nitin Nangare ${ }^{2}$, Dr. Aditya Phadke ${ }^{3}$, Dr. Tanmay Mehta ${ }^{4}$, Dr. Amit Verma ${ }^{5}$ \\ ${ }^{1}$ Associate Professor, Department of Surgery, Krishna Hospital, Karad, Maharashtra, India \\ ${ }^{2}$ Assistant Professor, Department of Surgery, Krishna Hospital, Karad, Maharashtra, India \\ ${ }^{3}$ Resident, Department of Surgery, Krishna Hospital, Karad, Maharashtra, India \\ ${ }^{4}$ Resident, Department of Surgery, Krishna Hospital, Karad, Maharashtra, India \\ ${ }^{5}$ Resident, Department of Surgery, Krishna Hospital, Karad, Maharashtra, India
}

\begin{abstract}
Wounds expose a patient to serious hazards like wound infection, tissue destruction, disfiguring and dis-abling scars. Use of superoxidised solution (oxum) in infected wounds, ulcers, diabetic wounds, abcesses, burns reduced morbidity and hospital stay with its early wound healing effect. To evaluate the effect of superoxidised water (Oxum) V/s povidone iodine (Betadine) on similar types of wounds. We retrospectively analysed the records of two hundred patients with different types of wounds who attended Department of Surgery, Krishna Hospital,Karad from January 2014 to January 2015. The patients were divided into two groups. Group A where topical management and dressing was done using oxum and group B where topical management and dressing was done using betadine. A standard grading in terms of percentage decrease in wound size, periwound oedema/ erythema, pus discharge and percentage increase in granula-tion, fibrin and epithelisation was noted in various types of wounds in both groups. Oxum treated wounds showed reduction in inflammation and their healing earlier than betadine group. Oxum application was safe having no pain and allergic manifestation.
\end{abstract}

Keywords: Superoxidised solution (oxum) . Povidone iodine (betadine) . Wounds

\section{Introduction}

Wounds and their management are fundamental in the practice of surgery. In trauma, road side accidents, stabs, war injuries, bites and burns, wound is frequently the primary pathology

The inflammatory phase of healing starts at the moment of injury. Initial vasoconstriction is followed by increased blood flow to the wound edges along with chemotaxis of polymorphs, macrophages, platelets and release of chemical mediators like cytokines and growth factors that activate and stimulate the healing process. Inflammatory phase (vasoconstriction followed by vasodilatation, platelet aggregation \& phagocytosis) is followed by proliferative phase \& granulation. Fibroblasts lay bed of collagen, fills defect and produces new capillaries. Contraction of wound edges pull together to reduce defect. Epithelization occurs across moist surface, cell travelling in all directions from point of origin. In remodelling phase new collagen forms which increases tensile strength of wounds.

Exogenous factors include duration of surgery, glove punctures, emergency procedures, air borne contamination, wound contamination, tissue perfusion, microbes causing infection.

Tissue level factors or local factors like poor blood supply, inadequate oxygenation undue tension in suturing, tissue necrosis and local infection have profoundly delete-rious effect on all aspects of wound healing.
Various growth factors stimulate cellular proliferation, chemotaxis, angiogenesis and enzyme production. Important growth factors include Platelet derived growth factor PDGF, fibroblast growth factors FGF, epidermal growth factor EGF, transforming growth factor TGF, insulin like growth factors IGF. The platelets are considered critical to initiation of healing as they are rich source of PDGF, PGF and EGF.

Various factors affecting wound healing are host related factors or endogenous factors. Healing is rapid in children and young persons and delayed in debilitated or malnourished having anemia and hypoproteinaemia. Obesity also has an adverse effect on wound healing. Uncontrolled diabetes results in reduced inflammation, angiogenesis and collagen synthesis. Jaundice and uraemia adversely affect wound healing. Wasting caused by chronic illness leads to poor wound healing. Malignancy is natural to cause poor wound healing. Patients on cytotoxic agents, chronic steroids intake and those having autoimmune deficiencies are more prone to wound infection and delayed healing.

Although a multimodel therapy is the basis of wound healing, an ideal antiseptic is one that is rapidly lethal to all forms of bacteria and their spores, capable of bactericidal activity for a prolonged period, has no injurious effect on wound healing tissues.

There has always been a search for an ideal antiseptic that is rapidly lethal to all forms of bacteria and their spores, capable of bactericidal property for a prolonged period with 


\section{International Journal of Science and Research (IJSR) \\ ISSN (Online): 2319-7064 \\ Index Copernicus Value (2013): 6.14 | Impact Factor (2015): 6.391}

no ill effect on host tissues. Superoxidized solutions may represent an alternative to the currently available antiseptics for the disinfection of skin and wounds. Superoxidized Solutions have shown to be both safe and efficient as a wound care product that moistens, lubricates, debrides and reduces the microbial load of various types of lesions [ 1 , 2]. Super oxidized solutions are elelctrochemically processed aquous solutions manu-factured from pure solutions which is rich in reactive oxygen species with neutral $\mathrm{pH}$ and longer half life ( $>12$ months). Oxum is a stable, non-flammable and non-corrosive bactericidal, virucidal, fungicidal and sporocidal solution that is ready to use with no further dilution or mixing.

\section{Ingredients}

Oxidized solution (H2O), sodium hypochlorite (NaOCI), Hypochlorous Acid (HOCI), Hydrogen peroxide (H2O2), Ozone (O3), Chlorine dioxide (ClO2), Sodium hydroxide $(\mathrm{NaOH})$, Sodium Carbonate (Na2CO3) and Sodium chloride $(\mathrm{NaCl})$.

\section{Mechanism of Action}

During the electrolysis process, solutions molecules are broken, ions and free radicals are formed. They rapidly react and denature proteins of bacterial cell wall. They also have anti-inflammatory effect and produce an environment with an unbalanced osmolarity that damages single cell organism. The damage is a direct result of the osmolarity difference between the concentrations of the ions in the solution versus the concentration of the same ions in the cell. Multicellular organisms are not prone to such osmolarity changes, therefore host tissues are spared. Once the single cell membrane is damaged, the ions in the product denature the bacterial proteins as well [ 3$]$.

\section{Material and Methods}

The present study was conducted to evaluate the effect of Superoxised water (Oxum) V/s Conventional dressing (Povidone Iodine) on similar type of wounds. The present study was conducted in total of 200 patients with 100 patients in each groups viz. Group A where dressing and topical management was done using superoxidised solution (oxum). Group B where dressing and topical management was done using betadine solution).

For this study patients having wounds (acute and chronic ulcers, diabetic foot ulcers, venous stasis ulcers, cellulitis, carbuncles, abscesses of different types, Burns, traumatic wounds, post surgical wounds, pressure/bed sores, fistula in ano, gangrenous wounds and internal irrigation like peritoneal lavage in peritonitis) were included in both the groups. Attempt was made to include similar types of cases in both the groups. The informed consent was taken in all the cases. The solution was applied to the wounds through different methods like washing, sprinkling, gauze dressing, immersion and irrigation.

Various investigations such as haemogram, blood Sugar, renal function tests (blood urea, S.creatinine), S.proteins
(TSP, DSP) S.electrolytes $\left(\mathrm{Na}+\mathrm{K}^{+}, \mathrm{Ca}^{++}\right)$, liver function tests (S.bilirubin SGOT, SGPT, S.Alkaline Phosphatase), pus swab for culture and sensitivity, radiological inves-tigations wherever indicated were carried out.

While doing operations and laparotomies nature of peritoneal fluid (whether mixed with blood/pus or faecal matter), condition of peritoneum and mesentery, adhesions with surrounding viscera, number, shape and size of perforation were noted.

The antibiotics were given in both the cases after culture and sensitivity wherever indicated. Observations were made during dressings and examination of the patients/wounds were done on day $1,3,5,7,9,12,14,18,21$ and noted in the written proforma.

The efficacy evaluation was based on appearance, presence or absence of odour, discharge, necrotic tissue, granulation tissue and epithelisation at the site of wound. The patients were also assessed based on symptoms such as pain, odema, redness, dryness and itching.

\section{Observations}

The present study comprising of 200 patients prospectively randomized into two groups of 100 patients each was conducted. Attempt was made to include patients having similar types of wounds in both the groups.

Group A where dressing and topical management was done using super oxidizing solution (Oxum). Group B where dressing and topical management was done using povidone iodine solution (Betadine).

The evaluation was based on healing of wound noting different parameters like reduction in size, discharge, pain, odema, redness, appearance of granulation tissue and epitheliasation of the wounds.

Needful debridement was done as and when needed and sufficient quantities of antiseptic solutions were applied to rinse the wound bed free of debris. The dressing was held in place with bandages wherever needed.

Survey and examination of wound was done on days 1, 5, 9, 12, 18 and 21 days respectively while doing dressings. At these visits complete physical examination, concomitant therapy, clinical examination of the wound and assessment of adverse effects were carried out.

A standard grading in terms of percentage decrease in wound size, peri-wound oedema/erythema, pus discharge and percentage increase in granulation, fibrin and epithelisation was noted. The above observations were based on use of measuring scale and clinical expertise. The findings were laid down for the evaluation of the wound and effect of the antiseptic solutions.

The reduction in wound size of wounds was significant right from the first dressings onwards. 


\section{International Journal of Science and Research (IJSR) \\ ISSN (Online): 2319-7064}

Index Copernicus Value (2013): 6.14 | Impact Factor (2015): 6.391

FIGURE SHOWING AVERAGE REDUCTIONIN WOUND SIZE ( $\%$ AGE) IN ACUTE ABSCESSES

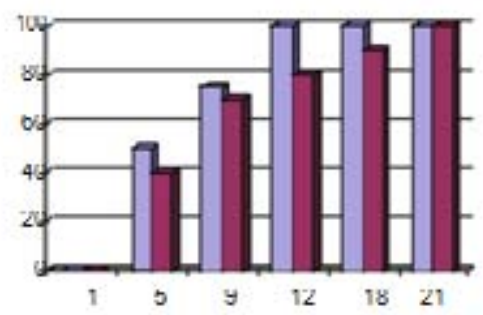

ZOxum Group a Betadine group
FIGURE SHOWING AVERAGE REDUCTION IN WOUND SIZE (9.6AGE) IN DIABETIC FOOT ULCERS

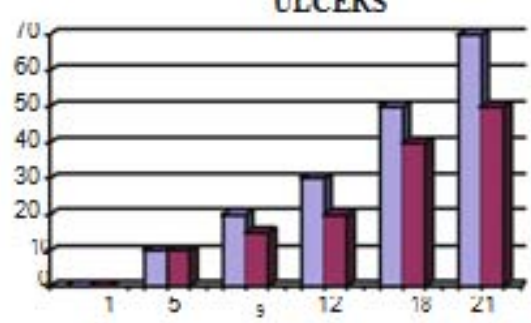

Goxum Group G Beadine group

Periwound swelling/ery-thema was recorded and its subsequent reduction from baseline was noted

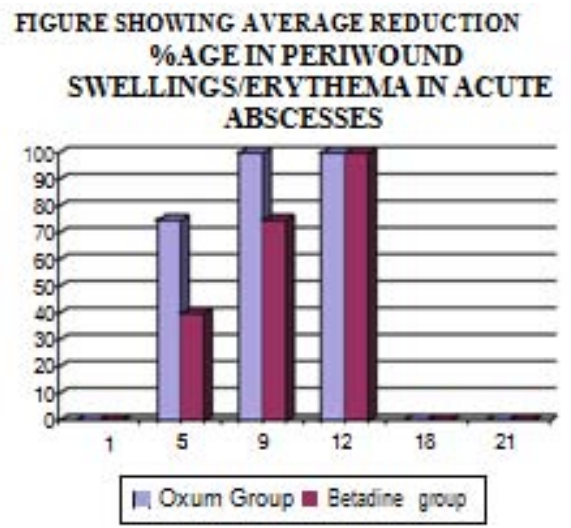

\section{FIGURE SHOWING AVERAGE REDUCTION \%AGE IN PERIWOUND SWELLINGS/ERYTHEMA IN VENOUS ULCERS}

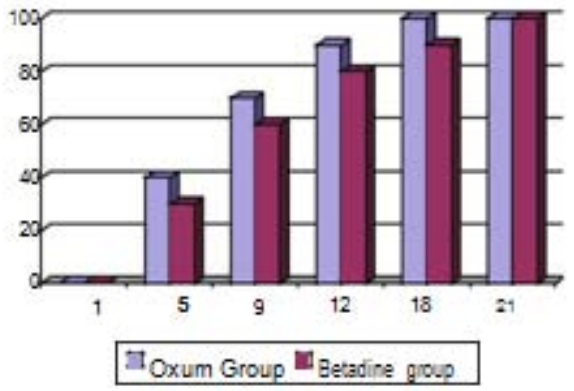

Reduction in pus/ discharge in fresh abrasions and traumatic wounds which were washed with normal saline and antiseptic solutions show no pus in the beginning but patient with diabetic foot ulcers, peritonitis, abscesses had pus on day 1 which was drained and needful debridement was done. The amount of pus decreased on subsequent visits and granulation appeared.

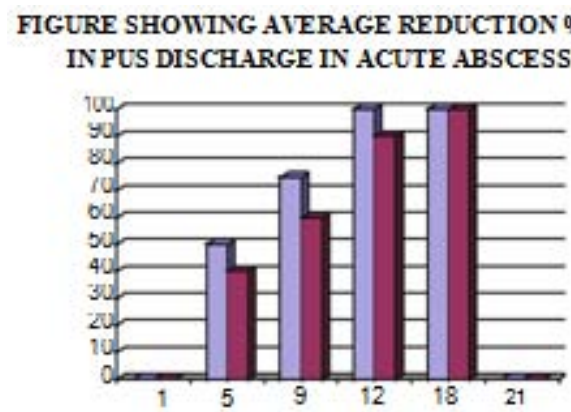

Y Oxum Group E Betadine group
FIGURE SHOWING AVERAGE REDUCTION \%AGE IN PUS DISCHARGE IN FOURNIER'S GANGRENE

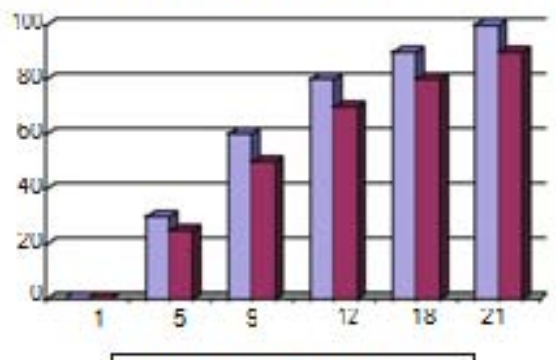

LE Oxum Group 盅 Betadine group

Granulation and epithelisation was not there in fresh and acute wounds but present to some extent in chronic wounds ulcers and bed sores. Increase in wound granulation followed by epithelisation was recorded during the study period.

FIGURE SHOWING INCREASE IN GRANULATION AND EPITHELISATION (\%AGE) IN BURNS

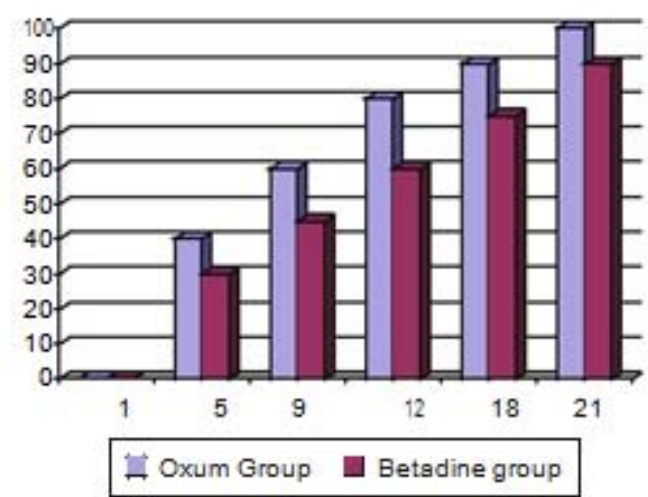

FIGURE SHOWING INCREASE IN GRANULATION AND EPITHELISATION (\%AGE) IN FISTULA IN ANO

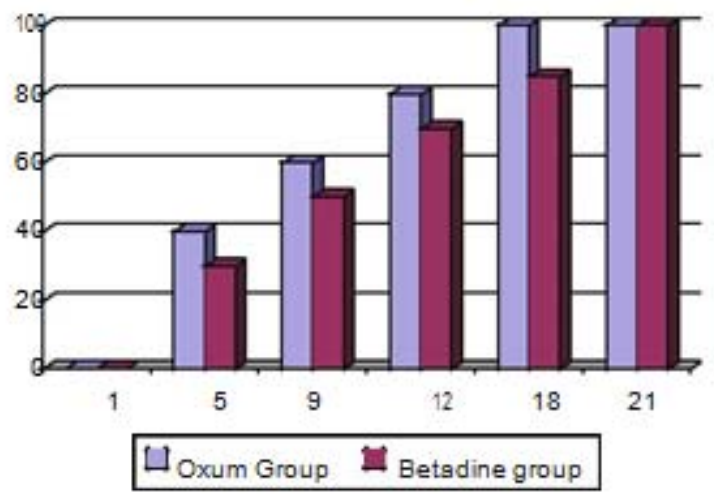




\section{International Journal of Science and Research (IJSR) \\ ISSN (Online): 2319-7064 \\ Index Copernicus Value (2013): 6.14 | Impact Factor (2015): 6.391}

\section{Discussion}

In the current study the affect of superoxidised water (oxum) $\mathrm{v} / \mathrm{s}$ povidone sodium on wound healing was studied.

In a study conducted by Dr. Luca Dalla Paola on 218 patients suffering from chronic diabetic foot ulcers 110 patients were treated with SOS(oxum) and 108 patients with povidone iodine. The mean healing time was lower in the oxum group (45 \pm 14$)$ days $\mathrm{v} / \mathrm{s}(58 \pm 20)$ days in betadine group [ 4].

In the current study diabetic foot ulcer and chronic leg ulcers patients treated with oxum shows early granulation and rapid epithelisation when compared to betadine group. The mean follow up of 21 days shows that average reduction in wound size and periwound odema/erythma in oxum group was $70 \%$ as compared to $50 \%$ in betadine group.

In a study conducted at the hospital Civil de Guadalajana in Mexico in 2004-05 with superficial-partial, deep-partial and full thickness burns the study group was treated with SOS (oxum) and was compared retrospectively with similar burns at the institution which had been treated with silver solutions/ointments (control group). In this trial only 6 patients received antibiotics in oxum group versus 56 in control group. Furthermore hospital stay was reduced by $50 \%$ in oxum group v/s control group [ 5].

In current study patients suffering from burns treated with oxum showed early recovery with less escher formation and better granulation and rapid healing. Furthermore irritation and pain while applying oxum was less when compared to betadine. The appearance of granulation tissue was more healthy with evidence of better microcirculation.

In another study all patients admitted to hospital Ruben Lenero in maxico in 2004-05 with generalized peritonitis were studied and peritoneal lavage was done with $5 \mathrm{~L}$ of SOS. The control group included similar patients in 200304 where peritoneal lavage was done using normal saline. In analysis of hospital stay in days control group had a longer stay (31.9 days) in comparison to study group (22.4 days) [ $6]$.

In the current study, 20 patients suffering from generilsed peritonitis were studied where laprotomy was done. While doing operation, peritoneal lavage followed by irrigation was done using oxum in 10 patients in group A and similar treatment was done using betadine in other patients in group B. Preoperative preparation and follow up dressing were also done using same solution. The study group showed better recovery, early appearance of bowel sounds and healthy wounds when compared with control group. The average length of hospital stays of patients treated with oxum was less number of days compared to betadine group.

Gutierrez in his study to explore various applications of superoxidised solutions concluded that the moistening effects and minimum toxicity found with the use of this superoxidised solution made it a good choice for wound care management [ 7].
Similarly, the global efficacy evaluation also confirms the superiority of oxum over povidone iodine as good to excellent efficacy response was recorded in relatively more number of patients in oxum treated group as compared to povidon-iodine treated group [ $2,8-11]$.

Many studies have been conducted which have proved its efficacy and safety in diverse conditions such as diabetic foot ulcer, venous stasis ulcers, bed sores, burns, cuts, absasions, post operative infective wounds, cellulitis and abscesses [ $1,4-6,9,12]$.

In current study average reduction in wound size and periwound odema/erythema was more with oxum. Pus discharge reduced earlier with early appearance of granulation and epithelisation proving oxum to be safe and efficient as a wound care product superior to povidone iodine.

\section{Summary and Conclusions}

The present study was undertaken to evaluate the comparative effect of SOS (oxum) v/s betadine on healing of different types of wounds. Two hundred patients having different types of wounds were included in the study.

Hundred patients were included in group A where dressing and management was done using SOS (oxum). Remaining 100 patients in group B were treated using povidone iodine. Attempt was made to include similar types of wounds in both the groups. Antibiotics were used in both the groups after taking a swab for culture and sensitivity prior to dressing. The following conclusions were drawn from the prospective study of two types of dressings.

- Swab culture was positive in 105 out of a total of 200 patients. Most commonly cultured organisms was staph aureus 42 (40\%) followed by Ecoli 37(35.2\%), pseudomonas 15(14.3\%), Strepto 11(10.5\%).

- No systemic or local allergic manifestation was seen in the study except mild irritation and pain during application of betadine especially in burns patients. There was no evidence of hepatotoxicity or nephrotoxicity.

- Oxum is safe and effective in all types of wound management and gives better efficacy and faster response as compared to traditional povidone iodine topical application.

- It has been demonstrated that there is remarkable reduction in common signs of inflammation like

- odema, erythema and remarkable increase in signs of healing of the ulcer i.e. granulation and fibrin formation.

- Global efficacy evaluation also confirms the superiority of SOS over povidone iodine as good to excellent- efficacy response was recorded in relatively more number of patients in oxum treated group as compared to povidone iodine treated group.

- Treatment with SOS reduces the microbial flora, is less painful during cleaning and debridement procedures. It can be used safely in various conditions such as diabetic foot ulcers, venous stasis ulcers, bed sores, burns, cuts, abrasions, post operative infective wounds, cellulites and abscesses. 


\section{International Journal of Science and Research (IJSR) \\ ISSN (Online): 2319-7064 \\ Index Copernicus Value (2013): 6.14 | Impact Factor (2015): 6.391}

- Burns treated with oxum heal easily with better cosmetic results and less chelation relative to previous standard treatment. Application is easy and treatment is less expensive compared to povidone iodine.

- The results of this study therefore appear to show more favourable results for oxum than for betadine. However, although the results are highly statistically significant, the strength of evidence depends upon the study design.

\section{References}

[1] Sekiya S, Ohmori K, Harii K (1997) Treatment of infectious skin defects or ulcers with electrolyzed strong acid aqueos solution. Artif Organs 21:32-38

[2] Tanaka H, Hirakata Y, Kaku M, Yashida R, Takemura $\mathrm{H}$ (1996) Antimicrobial activity of duper oxidized water. J Hosp Infect 34:43-49

[3] Oxum Product Monograph

[4] Dalla Paola L, Brocco E, Senesi A et al (2005) Use of Deracyn, a new antiseptic agent for the local treatment of diabetic foot ulcers. J Wound Heal 2:2012

[5] Miranda Altamirano A, Medina Preciado D, Chavez Velarde TJ et al (2005) Treatment of 2nd and 3rd Degree Burns in 64 Pediatric Patients Without Routine Antibiotics using New Super-oxidized Solution Technology" Texas Surgical Society Congress. San Antonio, Tx. 1st-3rd April, 2005 and European Burns Associa-tion Meeting 2005. Estoril Portugal

[6] Inouc Y, Endo S, Kondo K, Ito H, Onori H, Sarto K (1997) Trail of electrolysed strong acid aquous solution in the treatment of peritonitis and in abscesses. Artif Organs 21(1):28-31

[7] Gutierrez Andres A. The science behind stable super oxidized water exploring the various applications of super-oxidized solutions in clinical experience with a new and stable super-oxidized water in wound treatment, advanced wound care with stable, superoxidized water. Supplement to January 2006 Wound (A compendium of Clinical Research and Practice) Page 7-10

[8] Sakashita M, Iwasawa A, Nakamura Y (2002) Antimicrobial effect and efficacy on habitually hand washing of strong acidic electrolyzed water a comparative study of alcoholic

[9] Antiseptics and soap and tap water. Kansenshogaku Zasshi 76:373-377

[10] Wolvos Tom A. A look at how combination therapy can optimize wound healing in clinical experience with a new and stable super-oxidized water in wound treatment, advanced wound care with stable, superoxidized water. Supplement to January 2006 Wounds (A Compendium of Clinical Research and Practice) Page 11-13

[11] Middleton AM, Chadwick MV, Sanderson JL, Gaya H (2000) Comparison of a solution of super oxidized water (sterilox) with glutaraldehyde for the disinfection of bronchoscopes, contaminat-ed. J Hosp Infect 45:278282

[12] Landa-Solis C, Ganzalez-Espinosa D, Guzman-Soriano B et al (2005) Microcyn: a novel super oxidized water with neutral $\mathrm{pH}$ and disinfectant activity. J Hosp Infect 61:291-299

[13] Ohno H, Higashidate M, Yokosuka T (2000)
Mediastinal irrigation with superoxidized water after open heart surgery: the safety and pitialls of cardiovascular surgical applications. Surg Today 30:1055-1056 